\title{
Analysis of the Insertion of Particular Photovoltaic Generation in the Low Voltage Installations, Under the Approach to Performance, Safety, Maintenance and Operation of the PVS
}

\author{
Fillipe Alexandre Moraes ${ }^{1^{*}}$, Othavio Toniasso Takeda ${ }^{2}$
}

1 Programa de Pós-Graduação em Sistemas de Energia, Universidade Tecnológica Federal do Paraná, Curitiba, Brasil; 2 Programa de Pós-Graduação em Engenharia Civil, Universidade Tecnológica Federal do Paraná, Curitiba, Brasil.

\begin{abstract}
The growing use of Photovoltaic Solar Energy in Brazil, both in power plants and in distributed generation systems, brings with it a series of practical and technical questions that are not limited to the design and project of the systems. Environmental factors and resources related to the use, operation, maintenance, decommissioning and final disposal of the equipment and components that constitute them, should be taken into consideration, so that these systems maintain an adequate performance during their lifespan granting the safety for users, properties and avoid negative environmental impacts. Within the concept of Risk Analysis within the Life Cycle of these systems, the present study addresses a perspective of the growth of the use of Solar Photovoltaic Energy in Brazil and the risks and impacts resulting from the lack of information on how good practices for a maintenance of its facilities, its performance, safety and sustainability of Photovoltaic Solar Power Generation Systems.
\end{abstract}

Key-words: Photovoltaic Installations, Maintenance, Degradation, Reliability.

*Author for correspondence: fillipe1990@gmail.com 


\section{INTRODUCTION}

According to data ${ }^{5}$, the number of existing micro and mini-generators connections in the first quarter of 2015 was 507. In the second half of 2017, the number of connections in Brazil reached 10,561, representing a growth of 20 times over a period of only two and a half years.

In relation to the profile of consumers, the residential ones predominate with $79.5 \%$, commercial with $15 \%$, and in smaller percentages the rural and industrial connections with about $2 \%$ each. This consumption profile indicates that most Photo Voltaic Systems (PVS) are concentrated in residential and commercial buildings.

With the maturation of this market and the regulatory devices of the sector, in the distributed generation modalities contained in REN Resolution 482/2012, projections for the number of consumers in the residential and commercial market estimated by ANEEL for 2024 reach 886,700 consumer units, being 808,300 residential and 78,400 commercial. These figures demonstrate the proportions of the growth of this market and the potential of penetration of the systems of micro generation of photovoltaic solar energy in the built environment.

For each type of building, environmental characteristics, location, weather and type of installation should be considered in the projects, since different characteristics and intervenients can positively or negatively influence the performance of the generators, as well as the built environment where the systems are installed. This implies that in the design of the generation systems, in addition to specifying the electrical equipment used and the compatibility studies with the existing installations and structures, the specifications of the fastening materials, their form of execution / installation, interactions with other systems and maintenance activities during their uses should be considered, so that their durability is compatible with the lifespan of the system.

Both during the installation of the generators and in the activities of maintenance, decommissioning and discards; safety, maintainability and ergonomics, should also be included in the projects.

The feasibility of an PVS should take into account the Life Cycle Analysis of the system as a whole, aiming at the reliability of the assembly that composes the installation, looking for the minimization of risks and unrecorded indirect costs caused by failures, unscheduled outages, loss of performance and accidents that cause unavailability of the system and possible damages to people and property.

\section{MATERIAL AND METHODS}

For this article a bibliographical research was carried out to gather the most varied information and experiences of Experts, Researchers and Engineers who share their experiences in projects, installation and maintenance of PVSs.

\section{RESULT AND DISCUSSION}

\section{Residential and Commercial Standard of Electrical Installations in Brazil}

An electrical installation consists of the joint use of materials and equipment, conductors and non-conductors of electricity, which aim to transfer power flow to carry out a specific work, ensuring, necessarily, the safety of equipment and users ${ }^{1}$. Thus, in Brazil, electrical installations, especially those framed in low voltage, often do not follow the aforementioned definition, because in the design and maintenance, the installations are provided and maintained with unskilled labor most of the times, which in turn will compromise the safety of the PVS and its users. 
According to the technical standard ${ }^{4}$ of Companhia Paranaense de Energia (Copel), residential customers are divided into four categories of consumption: Low (0$75 \mathrm{kWh})$, Medium (76-150kWh), High (151-300kWh) and Very High (> 300kWh). In these cases, following the methods of Pinho and Galdino ${ }^{6}$, it can be observed that photovoltaic generators, for residential buildings, with consumption between 300 and $400 \mathrm{kWh} /$ month, easily present a continuous voltage around $500 \mathrm{Vdc}$. In commercial installations, this voltage can reach, in some cases, up to $1000 \mathrm{Vdc}$. In these situations, it is expected that the installation pattern will faithfully follow the safety requirements defined by ABNT NBR 5410 - Low Voltage Electrical Installations and by the Regulatory Norm NR10, as any electrical accidents with the voltage values presented may cause serious accidents: electric shocks, burns and fires, causing serious damage to people as well as to installations and buildings.

According to ABRACOPEL ${ }^{1}$, in the year 2016, 79\% of households in Brazil did not present protection items such as grounding and DR device. In this context, considering that residential installations are among those that most present fatal accidents with electric energy ${ }^{1}$, and that the individuals who are most exposed to risk situations are professionals who work directly with or depend on electricity to perform some type of activity $^{1}$; the integration of PVSs with pre-existing installations in buildings must be carefully analyzed, also observing aspects of compatibility, stability and reliability of all new and pre-existing installations.

\section{Methodology of Installation of Photovoltaic Systems}

In the execution of projects and installations of solar photovoltaic energy systems, national standards must be followed or, in case of lack of them, the support of international standards is necessary. Below are some rules and regulations related to the design, installation and operation of photovoltaic systems:

- $\quad$ NBR 5410 - Low Voltage Electrical Installations;

- $\quad$ NBR 5419 - Protection of Structures against Atmospheric Discharges;

- $\quad$ NR10 - Security in Facilities and Services in Electricity;

- $\quad$ NR35 - Work at height;

- $\quad$ NR33 - Confined Space Work;

- NBR 16274 - Network-Connected Photovoltaic Systems - Requirements, Documentation, Commissioning, Inspection and Performance Evaluation;

- NBR 16150 - Photovoltaic Systems - Connection Interface Characteristics with Distribution Electrical Network - Conformity Test Procedures;

- $\quad$ NBR 10899 - Photovoltaic Solar Energy - Terminology;

- $\quad$ RES no 482 e 687 / ANEEL - ANEEL Normative Resolutions;

- NBR 16280 - Building Reform - Reform Management System.

In order to guarantee the safety of persons and equipment, considering the mentioned technical standards, Pinho and Galdino ${ }^{6}$ present a summary of basic procedures that should be considered for the installation of an PVS:

- Follow the rules of the energy distributor to connect to the power grid;

- Restrict access to the work area;

- Attach warning signs or plates to the danger of electric shock, in the environment where the equipment is installed;

- Permanently keep the access door closed to environments where the controls, power conditioning equipment, measuring instruments or batteries are installed;

- Perform electrical grounding of metallic installations, equipment and structures;

- Install suitable electrical protection device for equipment and for human beings;

- Protect battery terminals to prevent accidental contact and / or short circuit; 
- Cover the photovoltaic generator with a blanket or opaque material when working on the system to reduce the risk of electric shock or accidental short circuit;

- Provide installation diagrams, safety manuals for operation and maintenance of the system;

- Make visible, in a visible place, instructions to disconnect the power of the equipment, before carrying out maintenance work, and to reconnect it after the end of the service;

- Remove all personal metallic objects before working on electrical installations;

- Provide personal protective equipment (PPE) and fire extinguisher for handling the installation.

In addition to the care inherent in the installation of PVSs, one must take into account the conditions of the built environment itself, where the interventions will be performed.

According to the best practices for the installation of $\mathrm{PVS}^{10}$ and the current Norms, the consultation of building projects and other professionals, in the case of doubts and clarifications, must be carried out prior to the design of the systems. A detailed inspection of the place where the facilities are to be evaluated should be carried out to identify the needs and elements that interfere with the assembly of the structures and also the safety, ergonomics and access of workers to the workplace.

Other implications arising from installations must be evaluated in order to guarantee the functionality and performance of other construction systems, such as waterproofing, roofing, structures, facades, among others, in order to reduce the possibility of loss of guarantee of these constructive systems with the builders and developers, for projects that are still in the legal guarantee period.

Exposure to weather and adverse environmental conditions should also be taken into account, since the fixation of the modules in the buildings must be analyzed within the context of the maintenance, the resistance of the substrates, structures and their connections; as well as their interactions with the environment, such as thermal movements, own weight and interactions with wind loads ${ }^{9}$.

Environments considered aggressive as Urban, Coastal and Industrial areas should be object of attention, providing that the structural elements, equipment and components of the PVSs be provided with coatings, protections and procedures of inspection, adequate cleaning and maintenance for the assurance of its integrity and performance during the lifespan of the system, ie at least 20 years or more.

Another important point is the quality of the fastening elements of the PVS support structures to the building. These shall be compatible with an expected durability of the structure itself and duly specified to avoid or minimize the possibility of the occurrence of the galvanic cell effect between metal elements in order to avoid foci of corrosion that would compromise as anchorages or collapse structures over the years. Specific PVSs characteristics isolated from the network must be considered ${ }^{9}$. When using Battery Banks, the environments where they are located should be suitable for this purpose, as their atmosphere tends to become aggressive over time. Problems of sulfation and corrosion in the contacts, as well as the interaction of the volatile components of the electrolytes used in the lead acid batteries with the humidity present in the environment, can make it corrosive, affecting not only the system components, but also the installations themselves, including the building itself, since it increases the probability of occurrence of pathologies in the structures of reinforced concrete by the change of the use. In these cases, adequate measures must be taken, both for the suitability of the environment for this purpose and for the maintenance of the conditions of use. 
In general, the compatibility of these facilities with the existing infrastructure should be considered. The planning and the necessary adaptations to the projects and the respective records in the as built, are important aspects to be considered in the PVSs applied to the buildings.

\section{Reliability, Performance and Sustainability of PVSs}

The reliability of grid-connected distributed generation systems has been of great concern to energy companies as well as to users ${ }^{7}$. The reliability and availability of large photovoltaic systems have not been thoroughly investigated. Manufacturers in the photovoltaic industry are offering guarantees of 20 years or more for photovoltaic modules with incomplete knowledge of their reliability in the various environments in which these modules will be deployed.

Data presented in Table 1, collected from modeling studies, on the reliability of the system components used in the Springerville (USA) plant, show that the inverter is the element that presents the greatest number of failures during the lifespan of a Photovoltaic System; 125 failures in 5 years, with an expectation of reaching 429 failures in 20 years of operation. The other equipment such as transformer, PV modules and junction box did not exceed 40 faults in a 5 -year period. And in a projection for 20 years, should not surpass 50 faults. Therefore, no system equipment is fault-free within the 25 year period ${ }^{2}$.

Table 1 - Modes of Failure in Photovoltaic Systems ${ }^{2}$

\begin{tabular}{lcccc}
\hline \multicolumn{1}{c}{ Components } & $\begin{array}{c}\text { Failures in 5 } \\
\text { years }\end{array}$ & $\begin{array}{c}\text { Expectation } \\
\text { failures in 5 years }\end{array}$ & $\begin{array}{c}\text { Expectation } \\
\text { failures in 10 } \\
\text { years }\end{array}$ & $\begin{array}{c}\text { Expectation } \\
\text { failures in 20 } \\
\text { years }\end{array}$ \\
\hline Inverter & 125 & 132 & 231 & 429 \\
\hline Photovoltaic Module & 29 & 26 & 31 & 38 \\
\hline Electrical Connections & 22 & 17 & 23 & 31 \\
\hline Lightning & 16 & 10 & 20 & 41 \\
\hline Transformer & 4 & 3 & 3 & 3 \\
\hline String Box & 34 & 25 & 35 & 50 \\
\hline
\end{tabular}

The components most susceptible to failures are the Inverters ${ }^{11}$; the inverters are composed of semiconductor modules and are the connection between the switching components and capacitors. Its reliability depends directly on the quality and performance of each of its components, mainly diodes and capacitors.

These findings have important repercussions in forecasting the payback period of the PVS and, consequently, in the viability of the projects and in the acceptance of the systems by the users in general. Although most systems reliability studies focus on large power plants; if we apply this approach to micro-generation systems in both networked and isolated systems, it is clear that for a system to be viable it is necessary, in addition to being well designed, that it ensures that its operation is adequate throughout its use and operation phase, allowing the system to reach its objectives in the long term, with adequate performance, sustainability promised by such technology.

\section{Maintenance of Photovoltaic Systems}

According to literature, PVSs in their general design are not maintenance free. They require a continuous monitoring regime in large systems, and periodic inspections, scheduled preventive maintenance and service calls when considering small and medium-sized systems. These actions generally aim at solving unplanned outages ${ }^{3}$. 
In a scientific study ${ }^{8}$, performance monitoring of 30 PVSs installed in Italy, which is part of the PERSIL (Solar Performance and Local Industry) program, was performed. The objective of the study was to develop a support tool to assist in the design, installation and maintenance of PVSs connected to the network. The detailed study discusses the various reasons for the low performance of some of the PVSs, identifies and analyzes a series of reasons for equipment failures, associates the reduction of their performance with system design flaws, design failures, installation errors, internal factors, environmental conditions and the lack of maintenance of the generators.

As a result of this study, a guide of good practices was presented for the Design, Installation and Maintenance of PVSs. As for design, the adoption of good practices leads to a greater reliability and availability of the systems and, consequently, to a lower number of equipment failures, reflecting a real performance closer to the simulations and forecasts obtained in the feasibility studies of the projects. Regarding installation, avoiding direct exposure of the conductors and inverters to the sun's rays and rain, obeying the removal of obstacles that can shadow the modules, providing suitable places for the installation of equipment sensitive to heat and humidity, making forecast adequate for ventilation and dissipation of heat in order to keep the temperature and humidity controlled, prediction of spaces and distances for the correct ventilation of the photovoltaic modules and allowing the movement of people during maintenance activities; are presented as determinants for the prevention of failures and for the maintenance of the lifespan of the $\mathrm{PVSs}^{8}$.

Finally, according to the author, the monitoring and maintenance of PVSs must consist of a continuous set of activities, and the monitoring of energy production (comparison between planned and performed) is the agent responsible for the identification of problems and deviations, since it accuses failure to operate the system, indicating a need for maintenance.

\section{Discussions}

Observing the history of the installation of PVSs in Germany, in 1000 systems connected to the electricity grid, between 1991 and 1995, when this modality of generation was still incipient and consolidated in that country, it was found that $40 \%$ of failures occurred due to problems with the installation, $30 \%$ due to project failures and the remainder for other reasons ${ }^{6}$. The training of skilled, qualified professionals is essential to avoid misunderstandings in both the projects and the deployments. The installer must be familiar with the operation of the system, not only his qualification in services with electricity and his capacities in services in height and with electricity (NR35 and NR10). This professional must have experience and knowledge about PVS singularities, in the Distributed Generation modality, for the adequate installation and safe maneuvering of PVSs during periodic maintenance schedules ${ }^{6}$.

The training of labor in the area of photovoltaic energy should consider four stages of training: basic, intermediate, advanced and specialized ${ }^{12}$.

The basic level comprises the local technical training, that is, it provides basic instruction so that the user can keep the system in operating conditions, with knowledge about its operation and safety maneuvers. The intermediate level comprises the qualification of electricians, or technicians in electricity, who will supply the maintenance of more complex problems, providing specific service so that the systems operate with the maximum reliability. Nevertheless, it is observed in practice that the professionals who operate in this sphere, are autonomous or professionals of the electricity that usually only bring with them concepts of traditional models of the electrical installations, ignoring the conceptions and modern practices of generation and supply of energy. The advanced level consists of the 
specific qualification of Engineers, who must assume responsibilities from the conception of the project until materialization of the system. Finally, the specialized training includes the technical training of professionals trained specifically in the field of knowledge of solar photovoltaic technology. These professionals must be able to carry out projects, solve technical problems, participate in coordination and management activities, transmit specific knowledge of the area, generate knowledge and, as a consequence, contribute to the social and technical training of other professionals in the sector at all levels. Such professionals usually are educated in existing programs of postgraduate in energy, in centers of reference present in Universities inside and outside Brazil.

\section{CONCLUSION}

The application or even integration of photovoltaic power generation systems with residential, commercial and industrial electrical installations promotes the intercommunication of technical disciplines that until recently went separately. The traditional model of generation, transmission and distribution of electric energy will be increasingly integrated with the built environment. This new conception requires a new technical and professional perspective on the part of the involved actors, because it brings with it new concepts and challenges.

In this new context, the formation of qualified and skilled labor is required, with the specific technical knowledge and skills capable of granting the technical and economic viability of the PVSs within the built environment, guaranteeing the users' safety, equity and realizing the benefits and the broader sustainability proposal for this alternative of renewable energy generation. Neglecting good practices and installation to omit costs, and thus make the commercialization of PVSs feasible, can contribute to the photovoltaic technology being discredited with investors and users and, instead of bringing benefits, to become another agent of promotion of danger to buildings and consumers.

\section{REFERENCES}

1 - Abracopel. [Brazilian Statistical Yearbook of Electrical Origin Accidents], Brasil, 2017.

2 - Collins E, Dvorack M, Mahn J, Mundt M, Quintana M. Reliability and Availability Analysis of a Fielded Photovoltalc Systemv. IEEE ind trans eléctron, pp.2316 - 2321, 2009.

3 - Enbar N, Key T. Addressing Solar Photovoltaic Operations and Maintenance Challenges, a Survey of Current Knowledge and Practices. Electric Power Research Institute EPRI White Paper; 2010.

4 - NTC 841001. [Urban distribution network design], Brasil, 1999.

5 - Technical note $\mathrm{n}^{\circ}$ 0056/2017-SRD/ANEEL.[Update of the projections of residential and commercial consumers with photovoltaic solar microgeneration in the horizon 2017 2024],Brasil, 2017

6 - Pinho JT, Galdino MA. [Engineering Manual for Photovoltaic Systems].Rio de Janeiro: gtes - cepel - dte - cresesb,2014.

7 - Roman E, Alonso R, Ibanez P, Elorduizapatarietxe S, Goitia D. Intelligent Pv Module for Grid-Connected PV Systems. IEEE Trans Ind Electron, 2006.

8 - Spertino F, Corona F. Monitoring and Checking of Performance in Photovoltaic Plants: A Tool for Design, Installation and Maintenance of Grid-Connected Systems. energy department, politecnico di torino, Italy, 2013

9 - Torres, DM. Sistemas Fotovoltaicos: [Development of a tool to support the designer and an installation manual] [dissertation], Faculdade de Ciências e Tecnologia da Universidade de Coimbra, 2009.

Braz. Arch. Biol. Technol. v.61, no.spe: e18000440 2018 
10 - Working Group NREAL. Best Practices in PV System Installation Version 1.0. Solar Access to Public Capital (SAPC) Working Group - NREL, March , 2015.

11 - Zhang P, Li W, Li S, Wang Y, Xiao W, Sawin J, et al. Reliability Assessment of Photovoltaic Power Systems: review of current status and future perspectives. Renewables 2010 global status report. Renewable Energy Policy Network; 2010 [Report No.: 1].

12 - Zilles R, Mocelin A, Morante F. [Brazilian Training and Certification Program for Installers of Small and Medium-sized Photovoltaic Systems], Avances em Energías Renovables y Medio Ambiente, Vol. 13, ISSN 0329-5184, Argentina, 2009. 